\title{
Influence of applied current density on the nanostructural and light emitting properties of $n$-type porous silicon
}

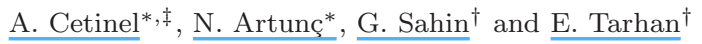 \\ *Department of Physics, Ege University, Bornova 35100, Izmir, Turkey \\ ${ }^{\dagger}$ Department of Physics, Izmir Institute of Technology, Urla 35430, Izmir, Turkey \\ ¥alper.cetinel@ege.edu.tr
}

Received 31 December 2014

Revised 23 February 2015

Accepted 24 February 2015

Published 15 April 2015

\begin{abstract}
Effects of current density on nanostructure and light emitting properties of porous silicon (PS) samples were investigated by field emission scanning electron microscope (FESEM), gravimetric method, Raman and photoluminescence (PL) spectroscopy. FE-SEM images have shown that below $60 \mathrm{~mA} / \mathrm{cm}^{2}$, macropore and mesopore arrays, exhibiting rough morphology, are formed together, whose pore diameter, pore depth and porosity are about $265-760 \mathrm{~nm}, 58-63 \mu \mathrm{m}$ and $44-61 \%$, respectively. However, PS samples prepared above $60 \mathrm{~mA} / \mathrm{cm}^{2}$ display smooth and straight macropore arrays, with pore diameter ranging from $900-1250 \mathrm{~nm}$, porosity of $61-80 \%$ and pore depth between $63-69 \mu \mathrm{m}$. Raman analyses have shown that when the current density is increased from $10 \mathrm{~mA} / \mathrm{cm}^{2}$ to $100 \mathrm{~mA} / \mathrm{cm}^{2}$, Raman peaks of PS samples shift to lower wavenumbers by comparison to crystalline silicon (c-Si). The highest Raman peak shift is found to be $3.2 \mathrm{~cm}^{-1}$ for PS sample, prepared at $90 \mathrm{~mA} / \mathrm{cm}^{2}$, which has the smallest nanocrystallite size, about $5.2 \mathrm{~nm}$. This sample also shows a pronounced PL, with the highest blue shifting, of about $12 \mathrm{~nm}$. Nanocrystalline silicon, with the smallest nanocrystallite size, confirmed by our Raman analyses using microcrystal model (MCM), should be responsible for both the highest Raman peak shift and PL blue shift due to quantum confinement effect (QCE).
\end{abstract}

Keywords: Porous silicon; nanostructure; Raman scattering; microcrystal model; photoluminescence; phonon confinement.

PACS numbers: 78.67.Bf, 61.46.-w, 78.30.-j, 61.46.Hk, 78.55.Mb, 33.20.Tp

\section{Introduction}

Since the formation of porous silicon (PS) layer on crystalline silicon (c-Si) wafer exhibits photoluminescence (PL) properties, PS has received a great deal attention

\footnotetext{
${ }^{\ddagger}$ Corresponding author.
} 


\section{A. Cetinel et al.}

to characterize and understand its properties. ${ }^{1}$ Light emitting PS layer has been produced by using different techniques, such as electrochemical anodization etching technique, ${ }^{1}$ stain etching process, ${ }^{2}$ and hydrothermal etching technique. ${ }^{3}$ Among these methods, anodization has been recognized as the most technologically feasible and economically superior technique for production of PS layer. Compared to other methods, the advantages of anodization technique are easy to control attribute, versatility and low cost. It has long been known that by varying the anodization parameters, such as concentration of hydrofluoric acid (HF), current density, time, doping type of substrate, etc., various PS samples with different structural, morphological and optical properties can be obtained. These controllable properties enable PS to be used in different areas, such as optoelectronics, ${ }^{4}$ microelectronics, ${ }^{5}$ chemical $^{6}$ and biological sensors. ${ }^{7}$

The first report of room temperature visible PL from PS fabricated by electrochemical anodization has attracted much attention from a fundamental physics viewpoint and because of the potential application to optical devices. ${ }^{1}$ The mechanism of visible PL from PS is not understood well. Several models have been proposed to explain PL from PS. ${ }^{8}$ However, the quantum confinement model (QCM) has been proved to be the most consistent with the experimental data. ${ }^{9}$ It is generally accepted that the size of the bandgap of silicon increases as a result of quantum confinement of electron-hole pair in reduced crystallite size and hence PL is shifted to visible spectral range..$^{9-11}$ It has been reported that the pore size, porosity and grain size in PS layer, which are believed to be the reasons for strong visible PL from PS at room temperature, strongly depend on the applied current density of the anodization. ${ }^{11-13}$ Therefore, structural investigation is essential for PS samples. Among several structural investigation techniques, Raman scattering spectroscopy is a nondestructive method and it can give us a lot of information related to the morphology and dimension of nanocrystals in PS. ${ }^{14}$ In addition, field emission scanning electron microscope (FE-SEM) and the gravimetric method are also used to investigate the surface morphology and the porosity of the samples, respectively.

Although numerous studies have already been reported on both fabrication and optical properties of PS, ${ }^{15,16}$ the influence of the current density alone on the nanostructure and optical properties of PS has rarely been reported which are focused only on $p$-type PS formed at low current densities. ${ }^{17,18}$ Hence, the aim of this study is to investigate the relationship between light emitting and structural properties of PS, by controlling the applied current density in the range from $10 \mathrm{~mA} / \mathrm{cm}^{2}$ to $100 \mathrm{~mA} / \mathrm{cm}^{2}$. Discussions on how other properties, such as the PS thickness, pore diameter, pore density, porosity and surface roughness, are influenced by the applied current density are also presented. We have also reported our results on the relationship between Raman scattering and PL spectra in the framework of the QCM by taking into consideration the effect of current density on nanostructures of PS samples. 


\section{Experimental Details}

The PS samples were prepared from (100) oriented and double-polished $n$-type silicon wafers (phosphor-doped) with a resistivity of 1-10 $\Omega \cdot \mathrm{cm}$ through electrochemical etching. Prior to etching, the wafer was cut into a constant area of $1 \mathrm{~cm} \times 1 \mathrm{~cm}$, and cleaned in acetone and distilled water, respectively. After that, the native $\mathrm{SiO}_{2}$ was removed by immersing the samples in $4 \% \mathrm{HF}$ aqueous solution for $5 \mathrm{~min}$. The PS layer was obtained by an anodic etch in ethanolic HF consisting of a 1:1 volume mixture of aqueous 40\% HF (Aldrich) and absolute ethanol (Merck) at a constant anodization time of $30 \mathrm{~min}$ and the temperature of ethanolic $\mathrm{HF}$ was kept at a constant value of $15^{\circ} \mathrm{C}$ and then air-dried. In electrochemical setup, silicon was the anode, $\mathrm{Pt}$ was the cathode in polypropylene cell. The anodization was performed under the illumination with $150 \mathrm{~W}$ halogen lamp and anodization current density was adjusted to be constant during etching by the use of a DC power supply. The current densities were in the range of $10-100 \mathrm{~mA} / \mathrm{cm}^{2}$. FE-SEM (FEI QUANTA 250 FEG) was used to investigate the surface morphology of PS samples. Thickness of PS layers was estimated by cross-section scanning electron microscopy (X-SEM). Porosity of the PS samples was calculated by the gravimetric method. MicroRaman measurements were performed at room temperature using S\&I Trivista Raman Spectroscopy system. Raman spectra of our PS samples were collected using an argon ion (488 nm) laser source, 1800 line/mm grating and $10 x$ objective. The spectrometer was calibrated against the $520 \mathrm{~cm}^{-1}$ transverse optical (TO) phonon frequency of $n$-type $\mathrm{Si}$ (100) wafer; the resolution of the spectrometer is $<2 \mathrm{~cm}^{-1}$. The PL spectra of the samples were measured by spectrophotometer at the room temperature, and the excitation wavelength was $488 \mathrm{~nm}$.

\section{Results and Discussion}

\subsection{Effect of applied current density on the pore structure of n-type porous silicon}

The effect of the applied current density on the surface morphology has been investigated for a constant HF concentration (20\%). The surface morphologies of PS samples are obtained with FE-SEM and shown in Figs. 1 and 2. FE-SEM images reveal that as the applied current density increases from $10 \mathrm{~mA} / \mathrm{cm}^{2}$ (maximum potential observed: $15 \mathrm{~V}$ ) to $100 \mathrm{~mA} / \mathrm{cm}^{2}$ (maximum potential observed: $90 \mathrm{~V}$ ), pore diameter of the PS samples increases from $265 \mathrm{~nm}$ to $1250 \mathrm{~nm}$, as summarized in Table 1. As can be seen in Figs. 1 and 2, the bright and dark regions represent the Si structures and pores, respectively. The images of PS samples indicate that the surface has no cracks in the applied current density range of $10-100 \mathrm{~mA} / \mathrm{cm}^{2}$.

Figure 1 also reveals that the porosity of the PS layers increases when the current density is increased from $10 \mathrm{~mA} / \mathrm{cm}^{2}$ to $100 \mathrm{~mA} / \mathrm{cm}^{2}$ at a constant $\mathrm{HF}$ concentration of $20 \%$. In Fig. 1, it is also observed that as the porosity of the PS layers increases the amount of the silicon in the structure becomes less, while the 

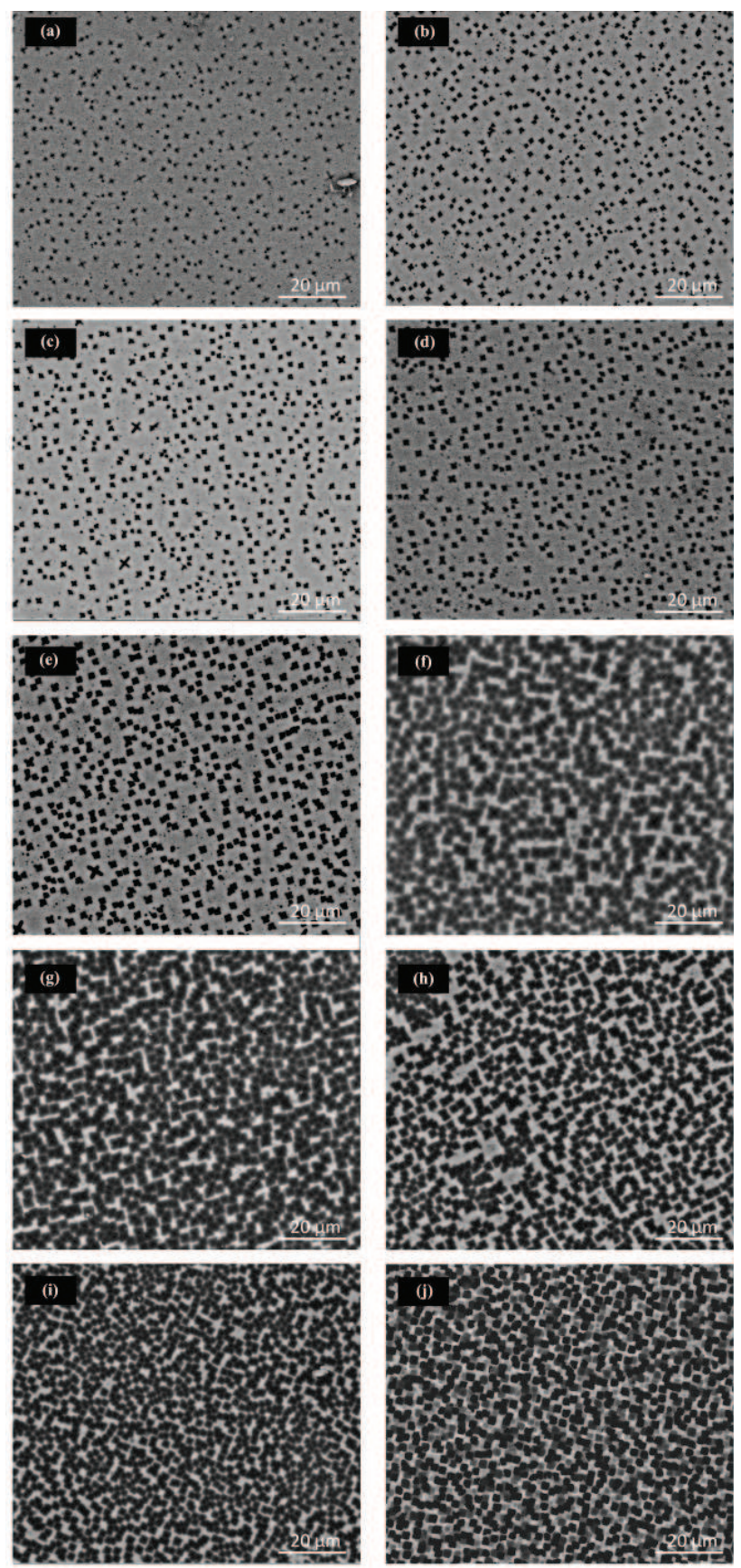

Fig. 1. (Color online) The top view FE-SEM images of PS samples prepared in $20 \%$ HF concentration at different current densities: (a) 10, (b) 20, (c) 30, (d) 40, (e) 50, (f) 60, (g) 70, (h) 80, (i) 90 and (j) $100 \mathrm{~mA} / \mathrm{cm}^{2}$. All samples are anodized for constant etching time of $30 \mathrm{~min}$, using $n$-type silicon (resistivity $1-10 \Omega \cdot \mathrm{cm}$ ) in solution composed of HF/Ethanol $(1: 1)$. 

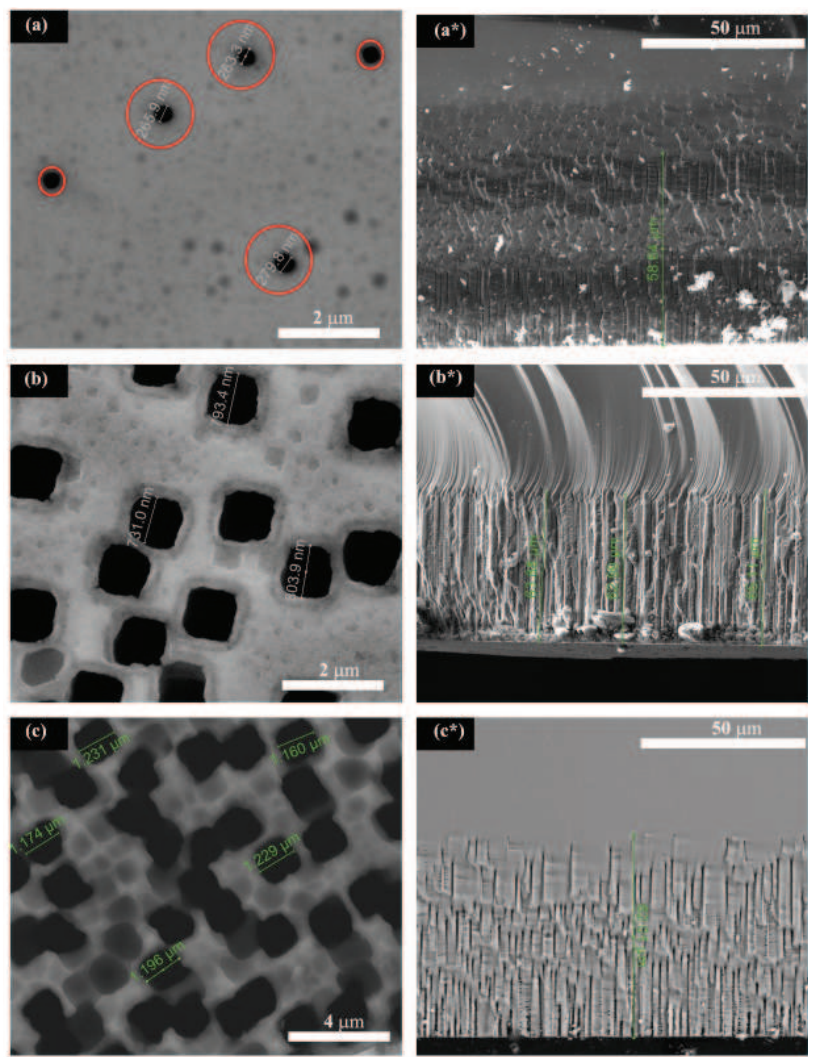

Fig. 2. (Color online) The top-view and cross-section FE-SEM images of PS samples prepared in $20 \% \mathrm{HF}$ concentration at different current densities: $\left(\mathrm{a}-\mathrm{a}^{*}\right) 10 \mathrm{~mA} / \mathrm{cm}^{2}$ (macropores are marked by circle), (b-- b*) $50 \mathrm{~mA} / \mathrm{cm}^{2}$ and $\left(\mathrm{c}-\mathrm{c}^{*}\right) 100 \mathrm{~mA} / \mathrm{cm}^{2}$.

Table 1. Anodization parameters and the PS samples' characteristics obtained by FE-SEM and gravimetric method.

\begin{tabular}{cccc}
\hline $\begin{array}{c}\text { Current } \\
\text { density } \\
\left(\mathrm{mA} / \mathrm{cm}^{2}\right)\end{array}$ & $\begin{array}{c}\text { Anodization time } \\
(\mathrm{min})\end{array}$ & $\begin{array}{c}\text { HF concentration } \\
(\%)\end{array}$ & $\begin{array}{c}\text { Pore diameter } \\
(\mathrm{nm})\end{array}$ \\
\hline 10 & 30 & 20 & 265 \\
20 & 30 & 20 & 375 \\
30 & 30 & 20 & 400 \\
40 & 30 & 20 & 625 \\
50 & 30 & 20 & 760 \\
60 & 30 & 20 & 900 \\
70 & 30 & 20 & 1000 \\
80 & 30 & 20 & 1200 \\
90 & 30 & 20 & 1250 \\
100 & 30 & 20 & 1220 \\
\hline
\end{tabular}




\section{A. Cetinel et al.}

Table 2. Anodization parameters and the PS samples' characteristics obtained by X-SEM and gravimetric method.

\begin{tabular}{ccccc}
\hline $\begin{array}{c}\text { Current density } \\
\left(\mathrm{mA} / \mathrm{cm}^{2}\right)\end{array}$ & $\begin{array}{c}\text { HF concentration } \\
(\%)\end{array}$ & $\begin{array}{c}\text { Anodization time } \\
(\mathrm{min})\end{array}$ & $\begin{array}{c}\text { Layer thickness (X-SEM) } \\
(\mu \mathrm{m})\end{array}$ & $\begin{array}{c}\text { Porosity } \\
(\%)\end{array}$ \\
\hline 10 & 20 & 30 & 58 & 44 \\
50 & 20 & 30 & 64 & 61 \\
100 & 20 & 30 & 62 & 79 \\
\hline
\end{tabular}

size of the pores increases and the interpore distance decreases. It is also known that PS has the same structure as bulk silicon. ${ }^{19}$ But when the porosity is in the range of $55-75 \%$, the lattice constant of the PS is 1-3\% larger than that of the bulk silicon. ${ }^{20,21}$ When the PS layer has the lattice mismatch with silicon substrate, a high residual stress (lateral and/or vertical stresses, depending on the applied current density and HF concentration) is expected to exist on their interface, which may cause the crack of the PS layer. ${ }^{19,20}$ Therefore, the PS sample formed at $100 \mathrm{~mA} / \mathrm{cm}^{2}$ is susceptible to both lateral and vertical stresses, resulting from a larger lattice mismatch at PS-Si interface, which is expected to alter Raman and PL peak positions of PS samples, as will be discussed in the following sections. X-SEM image of this sample (Fig. 2), indicating a slight decrease in the thickness, also confirms the above mentioned discussions (Table 2).

At low current densities $\left(<50 \mathrm{~mA} / \mathrm{cm}^{2}\right)$, macropores coexisting with mesopores are formed for an etching time of 30 min (Figs. 1 and 2). However, the formation of mesoporous silicon at current density greater than $60 \mathrm{~mA} / \mathrm{cm}^{2}$ is not observed. This result can be attributed to dissolution rate of silicon. ${ }^{22}$ As the current density increases from $20 \mathrm{~mA} / \mathrm{cm}^{2}$ to $100 \mathrm{~mA} / \mathrm{cm}^{2}$, etching speed increases gradually, hence the chemical dissolution of the PS increases and accordingly only macropores occur on PS layer.

In addition to FE-SEM analysis, porosity of PS samples is also calculated by the gravimetric method ${ }^{13}$ and summarized in Table 2 . In Table 2 , the porosity of PS increases with the increasing current density, in agreement with previous reports. ${ }^{23,24}$ Our X-SEM analysis reveal that the thickness of the PS samples is positively correlated with etching current density. It has been also evidenced from Fig. 2 that at the current density, varying from $10 \mathrm{~mA} / \mathrm{cm}^{2}$ to $40 \mathrm{~mA} / \mathrm{cm}^{2}$, macro-mesoporous layer with heavily branched morphology is fabricated. The pores are straight, but pore walls are of considerably rough morphology. The average diameter of (100) orientated main pores are between $265-625 \mathrm{~nm}$ and the porosity and depths are about $44-60 \%$ and $58-63 \mu \mathrm{m}$, respectively. As the current density is increased to $50 \mathrm{~mA} / \mathrm{cm}^{2}$, straight pores with $61 \%$ porosity, $64 \mu \mathrm{m}$ depths and average diameter of $760 \mathrm{~nm}$ are formed. The pore walls, formed at $50 \mathrm{~mA} / \mathrm{cm}^{2}$, are generally straight and their smoothness is better than that of the one obtained at $10 \mathrm{~mA} / \mathrm{cm}^{2}$. While current density is further increased to above $50 \mathrm{~mA} / \mathrm{cm}^{2}$, the macropore arrays are generally nice with the pore walls straight and rather smooth. The average diameter of stable macropores is between $900-1250 \mathrm{~nm}$, the depths and porosity are 
about $62-63 \mu \mathrm{m}$ and $61-80 \%$, respectively. As seen in Figs. 1 and 2, the shape of the pore is affected by the applied current density, and it changes from circular to square shape with increasing current density. Furthermore, PS layer has a columnar structure perpendicular to the Si substrate and the pores are not interconnected with each other (Fig. 2). In addition, some pores, which appear to be missing, seen in Figs. 2(a), $\left(\mathrm{b}^{*}\right)$ and $\left(\mathrm{c}^{*}\right)$, are actually through-channels. By cleaving the silicon substrate, it is impossible to obtain full cross sections of the pore arrays. ${ }^{25}$ X-SEM images of PS samples [Figs. $2\left(a^{*}\right),\left(b^{*}\right)$ and $\left(c^{*}\right)$ ] also reveal that as the applied current density increases, branched morphology of PS samples decreases. It has been pointed out that the low current density $\left(<50 \mathrm{~mA} / \mathrm{cm}^{2}\right)$ which produces small pores also favours the formation of branched structure. ${ }^{15,22,26}$ As the current density is decreased, silicon dissolution is suppressed, thus an increase of the branching tendency will consequently occur [Fig. 2(a*)]. ${ }^{15,22,26}$ In the case of high current density, silicon dissolution is strong, thus straight and smooth macropores without branching tendency are observed [Fig. 2(c*)]. From our SEM and X-SEM investigations, we can conclude that the pore size and morphology are very sensitive to the current density. In this study, wide range of porosities (from $44 \%$ to $80 \%$ ) and pore diameter (from $265 \mathrm{~nm}$ to $1250 \mathrm{~nm}$ ) are achieved by changing the current density from $10 \mathrm{~mA} / \mathrm{cm}^{2}$ to $90 \mathrm{~mA} / \mathrm{cm}^{2}$. It is well known that the macropores with diameters between $100 \mathrm{~nm}$ and $800 \mathrm{~nm}$ have a technological significance but become difficult to obtain for lightly doped $n$-type silicon wafer. ${ }^{25}$

\subsection{Effect of applied current density on the Raman spectra of n-type porous silicon}

Figures 3 and 4 show the Raman spectra of the PS samples prepared at different current densities, ranging from $10 \mathrm{~mA} / \mathrm{cm}^{2}$ to $100 \mathrm{~mA} / \mathrm{cm}^{2}$, under constant $\mathrm{HF}$ concentration (20\%). The Raman spectrum from our reference $n$-type c-Si substrate is also shown as a comparison in Figs. 3 and 4. The first-order TO phonon centered at $520 \mathrm{~cm}^{-1}$ with a full width at half maxima (FWHM) of $2.4 \mathrm{~cm}^{-1}$ for our reference c-Si sample is seen in Figs. 3 and 4. It should be noted that there is no evidence of amorphous phase at $480 \mathrm{~cm}^{-1}$ in the measured Raman spectra of all PS samples (Figs. 3 and 4). Apart from this, we cannot assign any Raman peak to the defects, causing a significant effect on the Raman spectra of our PS samples in Figs. 3 and 4. Moreover, we also found two broad peaks at $302 \mathrm{~cm}^{-1}$ and $616 \mathrm{~cm}^{-1}$ in all PS spectra (Fig. 3). We have observed a weak peak at $302 \mathrm{~cm}^{-1}$ which is from the scattering of two transverse acoustic (2TA) phonons in the Raman spectra of our PS samples (Fig. 3). ${ }^{27}$ The appearance of a broad peak at $616 \mathrm{~cm}^{-1}$, which is from the scattering of two transverse optic (2TO) phonons, in the spectra of PS samples is expected as the typical characteristic of PS. ${ }^{28}$ Both weak and broad peaks should be ascribed to the quantum confinement effect (QCE) of nanocrystals among the walls in PS samples. ${ }^{29}$ Therefore, we may identify these observed spectra as the intrinsic Raman spectra of our PS samples. It can be seen in Fig. 3 that the intensities of 


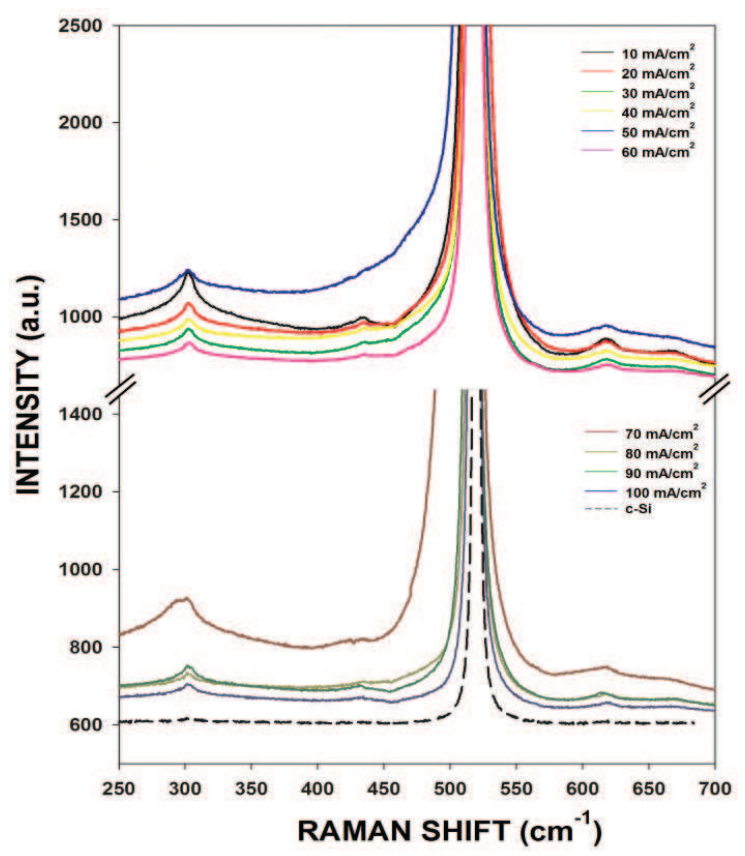

Fig. 3. (Color online) Raman spectra of reference c-Si and PS samples prepared in $20 \% \mathrm{HF}$ concentration at different current densities ranging from $10 \mathrm{~mA} / \mathrm{cm}^{2}$ to $100 \mathrm{~mA} / \mathrm{cm}^{2}$. Raman Spectra of c-Si and PS samples were collected using an argon ion (488 nm) laser source.

two broad peaks at 302 and $616 \mathrm{~cm}^{-1}$ in all PS spectra are significantly decreased with increasing applied current density from $10 \mathrm{~mA} / \mathrm{cm}^{2}$ to $100 \mathrm{~mA} / \mathrm{cm}^{2}$.

Now we can concentrate on the changes in the first-order TO phonon mode of our PS samples. As can be seen in Fig. 4, as the applied current density increases from $10 \mathrm{~mA} / \mathrm{cm}^{2}$ to $100 \mathrm{~mA} / \mathrm{cm}^{2}$, the Raman spectra of PS samples show asymmetrical broadening and peak positions shift to a lower wavenumber relative to our reference c-Si. From Fig. 4 and Table 3, we have observed that the Raman peak positions shift from $520 \mathrm{~cm}^{-1}$ down to $518 \mathrm{~cm}^{-1}$, and that the FWHM increases from $2.4 \mathrm{~cm}^{-1}$ to $4.7 \mathrm{~cm}^{-1}$, as the current density increases in the range of $10-100 \mathrm{~mA} / \mathrm{cm}^{2}$. It should be also pointed out that as the current density increases from $20 \mathrm{~mA} / \mathrm{cm}^{2}$ to $90 \mathrm{~mA} / \mathrm{cm}^{2}$, the Raman peak positions shift to lower wavenumbers from $520 \mathrm{~cm}^{-1}$ to $516.8 \mathrm{~cm}^{-1}$, about $3.2 \mathrm{~cm}^{-1}$ (the highest shifting), relative to c-Si, whereas at the current density of $100 \mathrm{~mA} / \mathrm{cm}^{2}$, Raman peak position shows a smaller shifting from $520 \mathrm{~cm}^{-1}$ to $518 \mathrm{~cm}^{-1}$, about $2 \mathrm{~cm}^{-1}$. The first effect can be explained in terms of the decreasing Si nanocrystallite size (or with increasing porosity), yielding an increase in surface-induced residual stress (lateral stress) with increasing current density ${ }^{19,21,30}$ as confirmed by our FE-SEM and Raman analyses. However, a smaller Raman peak shift observed in the sample of $100 \mathrm{~mA} / \mathrm{cm}^{2}$ can be caused by a slightly larger nanocrystallite size, resulting in a slightly larger residual stress 


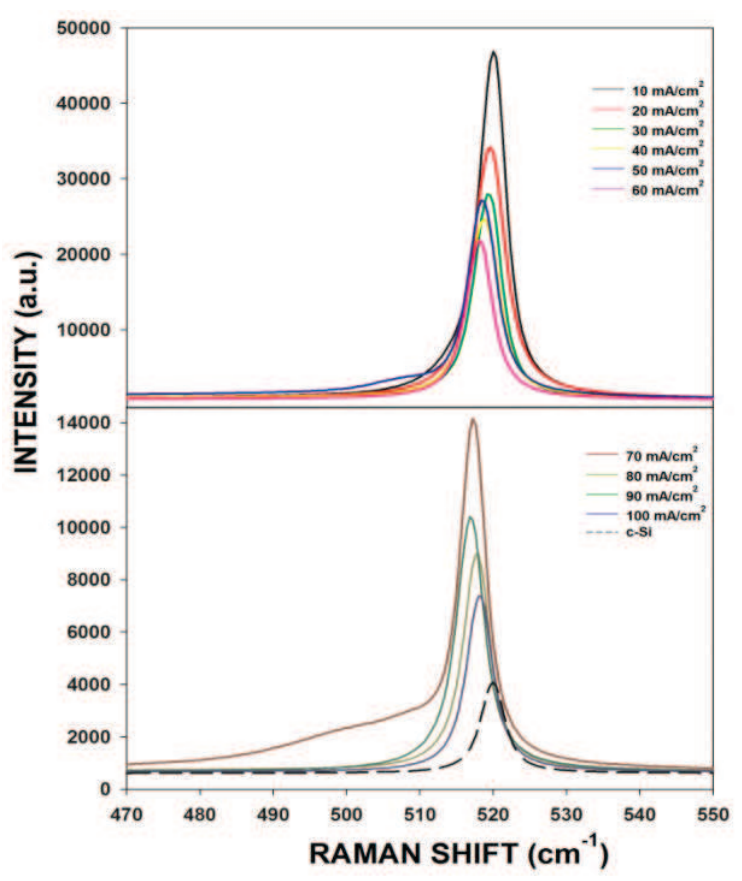

Fig. 4. (Color online) Raman spectra of TO phonon modes for c-Si and PS samples prepared in $20 \% \mathrm{HF}$ concentration at different current densities ranging from $10 \mathrm{~mA} / \mathrm{cm}^{2}$ to $100 \mathrm{~mA} / \mathrm{cm}^{2}$.

(in this case, both lateral and vertical stresses operate simultaneously) than those of the PS samples of $70-90 \mathrm{~mA} / \mathrm{cm}^{2}$, due to the decreasing of quantity of silicon within the PS in consistent with QCE. ${ }^{19,20,29,30}$ Based on the QCE, these observed shifts in the Raman spectra of the PS samples toward a lower wavenumbers, compared with c-Si and broadening of the peaks, with increasing current density from $10 \mathrm{~mA} / \mathrm{cm}^{2}$ to $100 \mathrm{~mA} / \mathrm{cm}^{2}$ can be attributed to the confinement of phonons in $\mathrm{Si}$ nanocrystals among the pore walls. ${ }^{11,14,28,29}$

It has been reported that when nanocrystallite size is decreased, the larger shifts in the peak positions and more asymmetric and broader lineshape are observed in the Raman spectra of PS samples. ${ }^{31,32}$ These features can be supported by our Raman analyses, where we have determined nanocrystallite size of our PS samples. Different confinement models have been used to calculate particle size. ${ }^{32-34}$ In order to explain our experimental results in Fig. 4, we have calculated the size of silicon nanocrystallites using MCM based on the QCE, because MCM has been successfully applied to many nanoscale materials. ${ }^{27,28}$ The calculated size of nanocrystallite has been summarized in Table 3. Our Raman analyses have also revealed that the smallest nanocrystallite size of $5.2 \mathrm{~nm}$ is obtained for the samples prepared at $90 \mathrm{~mA} / \mathrm{cm}^{2}$ in a fixed $\mathrm{HF}$ concentration of $20 \%$. It should be noted that there is a good agreement between nanocrystallite sizes of our PS samples calculated from Raman spectra using MCM and the nanocrystallite sizes determined 


\section{A. Cetinel et al.}

Table 3. Spectral parameters determined from Raman analysis and calculated crystallite size using microcrystal model (MCM) based on QCE.

\begin{tabular}{cccccccc}
\hline Samples & $\begin{array}{c}\text { Raman } \\
\text { frequency } \\
\left(\mathrm{cm}^{-1}\right)\end{array}$ & $\begin{array}{c}\text { Raman } \\
\text { Shift } \\
\left(\mathrm{cm}^{-1}\right)\end{array}$ & $\begin{array}{c}\text { Intensity } \\
(\text { a.u. })\end{array}$ & $\begin{array}{c}\text { FWHM } \\
\left(\mathrm{cm}^{-1}\right)\end{array}$ & $\begin{array}{c}\text { Crystallite } \\
\text { Size } \\
(\mathrm{nm})\end{array}$ & $\begin{array}{c}\text { Coefficient } \\
\text { of } \\
\text { Broadening } \\
\left(C_{b}\right)\end{array}$ & $\begin{array}{c}\text { Asymmetric } \\
\text { Coefficient } \\
\left(C_{a}\right)\end{array}$ \\
\hline c-Si & 520 & - & 4082 & 2.4 & - & 1 & 1 \\
10 & 520 & - & 46,851 & 4.6 & - & 1.44 & 1 \\
20 & 519.6 & 0.4 & 34,176 & 4.5 & 14.9 & 1.31 & 1.16 \\
30 & 519.2 & 0.8 & 27,951 & 4.7 & 10.5 & 1.98 & 1.17 \\
40 & 518.8 & 1.2 & 24,629 & 5.1 & 8.6 & 2.05 & 1.19 \\
50 & 518.4 & 1.6 & 27,144 & 5.1 & 7.4 & 2.05 & 1.20 \\
60 & 518 & 2 & 21,843 & 5.1 & 6.6 & 2 & 1.20 \\
70 & 517.2 & 2.8 & 14,149 & 5 & 5.6 & 1.99 & 1.19 \\
80 & 517.6 & 2.4 & 8977 & 4.8 & 6 & 1.94 & 1.18 \\
90 & 516.8 & 3.2 & 10,403 & 5.5 & 5.2 & 2.25 & 1.21 \\
100 & 518 & 2 & 7379 & 4.7 & 6.6 & 1.98 & 1.18 \\
\hline
\end{tabular}

from QCE in previous studies. ${ }^{27-29}$ Table 3 shows the spectral parameters and calculated nanocrystallite size of PS samples. The spectral parameters are the Raman wavenumber, the Raman shift relative to the Raman wavenumber of c-Si, the FWHM, the coefficient of broadening $\left(C_{b}\right)\left(\mathrm{FWHM}_{\mathrm{PS}} / \mathrm{FWHM}_{\mathrm{C}-\mathrm{Si}}\right)$ and the asymmetric coefficient $\left(C_{a}\right)$ (LWHM/RWHM, where LWHM and RWHM are the left width at half maximum and the right width at half maximum from the central peak position, respectively). From Table 3, we have found that the Raman shift and asymmetric coefficient $\left(C_{a}\right)$ of PS samples increase, while nanocrystallite size and peak intensity of PS samples decrease, as the applied current density is increased from $10 \mathrm{~mA} / \mathrm{cm}^{2}$ to $100 \mathrm{~mA} / \mathrm{cm}^{2}$. It can be seen in Fig. 4 and Table 3 that by increasing the applied current density, peak intensity of our samples decreases from 46851 (a.u.) to 7379 (a.u.). It is well known that Raman peak intensity is proportional to Si density. ${ }^{31}$ In our study, when the porosity increases, Si density decreases because of pore diameter increase as confirmed by FE-SEM investigation. Based on our Raman investigation, we can conclude that this observed decrease in Raman intensity of PS samples is resulted from different absorptions of probe light, scattered and reflected inside pores. ${ }^{27}$ As can be seen in Tables 1 and 3, Raman peaks shift from $520 \mathrm{~cm}^{-1}$ to $516.8 \mathrm{~cm}^{-1}$ and broadening of the peak FWHM from $2.4 \mathrm{~cm}^{-1}$ (symmetric) to $5.5 \mathrm{~cm}^{-1}$ (asymmetric) are observed with increasing pore diameter from $265 \mathrm{~nm}$ to $1250 \mathrm{~nm}$, that is, decreasing nanocrystallite size from $15 \mathrm{~nm}$ to $5.2 \mathrm{~nm}$ thereby changing the applied current density from $10 \mathrm{~mA} / \mathrm{cm}^{2}$ to $90 \mathrm{~mA} / \mathrm{cm}^{2}$. It has been pointed out that when the nanocrystallite size is less than $100 \AA$, a significant contribution of the Raman scattering belongs to those phonons as observed in Raman spectra of PS, whose wave vectors have been stuck out of the Brillouin zone. ${ }^{28,29}$ Thus, these 
Table 4. Effect of applied current density on PL parameters of PS samples.

\begin{tabular}{ccccc}
\hline $\begin{array}{c}\text { Current } \\
\text { density } \\
\left(\mathrm{mA} / \mathrm{cm}^{2}\right)\end{array}$ & $\begin{array}{c}\text { Peak maximum } \\
(\mathrm{nm})\end{array}$ & $\begin{array}{c}\text { Peak intensity } \\
(\text { a.u. })\end{array}$ & $\begin{array}{c}\text { Crystallite size } \\
(\mathrm{nm})\end{array}$ & $\begin{array}{c}\text { Pore diameter } \\
(\mathrm{nm})\end{array}$ \\
\hline 10 & 692 & 1096 & - & 265 \\
20 & 687 & 1362 & 14.9 & 375 \\
30 & 687 & 1499 & 10.5 & 400 \\
40 & 686 & 2032 & 8.6 & 625 \\
50 & 686 & 2123 & 7.4 & 760 \\
60 & 684 & 2391 & 6.6 & 900 \\
70 & 683 & 4826 & 5.6 & 1000 \\
80 & 684 & 3464 & 6.0 & 1200 \\
90 & 680 & 15838 & 5.2 & 1250 \\
100 & 684 & 2340 & 6.6 & 1220 \\
\hline
\end{tabular}

observed shifts in the Raman peaks toward lower wavenumbers and broadening of the peaks with increasing pore diameter and porosity (or with decreasing crystallite size) can be attributed to the confinement of optical phonons in nanodimensional Si nanocrystallites among the walls.

\subsection{Effect of applied current density on the PL spectra of n-type porous silicon}

PL spectra of PS give the information of a cross-sectional view of the silicon nanocrystals which remain among the pores, owing to the large optical penetration depth. PL is directly related to the electronic structure and transition. ${ }^{35}$ Therefore, in this study, the effects of current density on the electronic structure of PS, thereby the changes in nanocrystallite size, porosity and pore size of PS samples, induced by varying applied current densities were also investigated by PL measurements. The PL spectra of PS samples were measured at room temperature and recorded in the range of 580-790 nm, presented in Fig. 5 and Table 4. It can be seen from Fig. 5 and Table 4 that PL starts to appear at nanocrystallite size below $8.6 \mathrm{~nm}$ (that is, the pore size above $625 \mathrm{~nm})$, corresponding to the current density $\geq 40 \mathrm{~mA} / \mathrm{cm}^{2}$. From Fig. 5 and Table 4, in the current density range of $10-80 \mathrm{~mA} / \mathrm{cm}^{2}$ the PL peak positions of PS samples shift gradually toward lower wavelengths, about 5$8 \mathrm{~nm}$, while at $90 \mathrm{~mA} / \mathrm{cm}^{2}$ it shows a pronounced blue shifting, about $12 \mathrm{~nm}$, and also a remarkable increase in intensity, about 15,838 (a.u.) (corresponding to the smallest nanocrystallite size of $5.2 \mathrm{~nm}$ and also the largest pore size of $1250 \mathrm{~nm}$ and porosity $80 \%$ ) and then starts to slightly decrease as current density is increased up to $100 \mathrm{~mA} / \mathrm{cm}^{2}$, at which, nanocrystallite size starts to increase, from $5.2 \mathrm{~nm}$ to $6.6 \mathrm{~nm}$. This observed increase in the blue shifting of our PS samples, with increasing current density of $20-90 \mathrm{~mA} / \mathrm{cm}^{2}$ can be explained in terms of the similar discussions of Raman peak shifting, corresponding to the samples prepared at same current densities. Therefore, the observed increase in the amount of 
A. Cetinel et al.

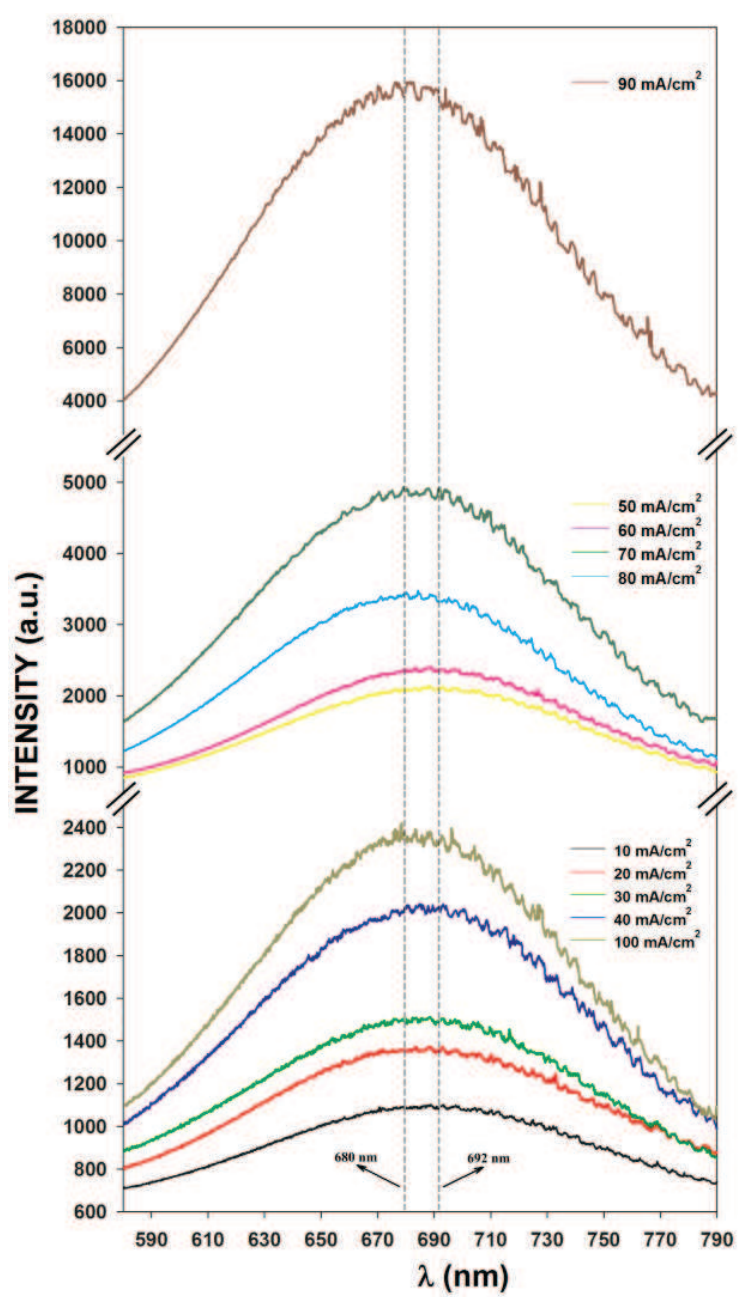

Fig. 5. (Color online) Room temperature PL from PS samples prepared in $20 \%$ HF concentration at different current densities ranging from $10 \mathrm{~mA} / \mathrm{cm}^{2}$ to $100 \mathrm{~mA} / \mathrm{cm}^{2}$. Spectra were taken with $488 \mathrm{~nm}$ excitation source focused on the sample. Dash lines show PL peak maximum at $680 \mathrm{~nm}$ and $692 \mathrm{~nm}$ for the samples $90 \mathrm{~mA} / \mathrm{cm}^{2}$ and $10 \mathrm{~mA} / \mathrm{cm}^{2}$, respectively.

PL blue shifting to lower wavelengths, over the current densities of $20-90 \mathrm{~mA} / \mathrm{cm}^{2}$ should be also caused by decreasing Si nanocrystallite size, resulting in an increased surface-induced residual stress (lateral stress), causing a smaller lattice mismatch, compared with c-Si substrate. ${ }^{19-21,36}$ Whereas, observed slight decrease in the PL blue shifting at the current density of $100 \mathrm{~mA} / \mathrm{cm}^{2}$ can be explained in terms of slightly larger Si crystallite size, causing a slightly larger lattice mismatch at Si-PS interface, induced by larger residual stress (both lateral and vertical stress) with respect to those of the PS sample of $90 \mathrm{~mA} / \mathrm{cm}^{2}{ }^{19-21,36}$ Accordingly, it can be concluded that Raman and PL behaviors of our PS samples are combined effects 
of the Si nanocrystallite size (or porosity) and the residual stress, due to the applied current density. Smaller Si nanocrystallite size, which leads to QCE, causes blueshift in PL spectra, whereas the residual stress determines the amount of the blue shifting. ${ }^{35}$

Based on our PL analysis, we can conclude that PL peaks of our PS samples are related to the S-band, which extends blue-red spectral range and they show a blueshift, about $12 \mathrm{~nm}$, over the wavelength range of $692-680 \mathrm{~nm}$, with increasing current density from $10 \mathrm{~mA} / \mathrm{cm}^{2}$ to $90 \mathrm{~mA} / \mathrm{cm}^{2}$. The best PL efficiency is observed for PS sample, prepared at current density of $90 \mathrm{~mA} / \mathrm{cm}^{2}$ around $680 \mathrm{~nm}$. These observed effects can be explained satisfactorily in terms of the QCE. ${ }^{1,35}$ Bulk silicon has an indirect bandgap and does not show any PL peak, while PS structures have been reported to have efficient luminescence in a range, extending from the near-infrared (IR) to the blue region of the visible spectrum. ${ }^{35}$ The observed PL can be assigned to three luminescence bands: The F-band luminescence which corresponds to the blue-green emission $(\sim 470 \mathrm{~nm})$, the S-band luminescence which corresponds to the blue-red emission (400-800 nm) and the IR-band corresponding near-IR spectral range (1100-1500 nm) luminescence. Among these three luminescence bands, the red PL band is usually the most intense. The PL peak position of the red band extends from about $1.3 \mathrm{eV}(950 \mathrm{~nm})$ to $2.1 \mathrm{eV}(590 \mathrm{~nm})$. The PL peak position of the red band can be shifted by the variation of the anodization parameters. A blueshift is observed for an increase in applied current density, for a decrease in nanocrystallite size and for an increase in porosity and pore diameter of PS samples, in agreement with our FE-SEM and Raman results.

As mentioned above, higher current densities produce PS samples with relatively smaller nanocrystallite size and higher porosity. Accordingly, increasing current density, leading to a significant increase in the PL blueshift and peak intensity, is a strong indication that silicon nanocrystallite size approaches the dimension of a free exciton (i.e., $\sim 5 \mathrm{~nm}$ ) of bulk Si. According to the QCE, the average size of nanocrystallites in PS is expected to get smaller and make a blueshift in PL peaks, with the increasing applied current density. ${ }^{1,10,11,14,29,31,36}$ Based on the origin of the luminescence, this blueshift increase should be resulting from the quantum-sized silicon crystallites among the walls, or from the defect and the species formed during the anodization process in Si complexes including amorphous silicon, siloxene and Si hydrides. ${ }^{8}$ According to our Raman scattering analysis, we have not observed a broad peak at $480 \mathrm{~cm}^{-1}$, indicating that there is no substantial contribution to the Raman intensity from possible amorphous silicon on the PS surface. Furthermore, we have not observed any defect in the PS layer, which is presented in Raman spectra. The results of our analysis support the basic model depicted by Canham, ${ }^{1}$ in which the source of the luminescence is due to the quantum confinement. Consequently, our PL analysis reveals that applied current density has a significant effect on the electronic structure and accordingly on the light emitting properties of our PS samples. 


\section{A. Cetinel et al.}

\section{Conclusion}

In this study, the effects of applied current density on the surface morphology and light emitting properties of PS samples have been investigated by a combination of FE-SEM, X-SEM, Raman and PL spectroscopy. From our FE-SEM and X-SEM investigations, we have concluded that the pore size and morphology are very sensitive to applied current density. The Raman spectra of PS samples show asymmetrical broadening and peak shifting to lower wavenumbers, relative to the our reference c-Si line position of $520 \mathrm{~cm}^{-1}$, with increasing applied current density. We have found that PS sample formed at $90 \mathrm{~mA} / \mathrm{cm}^{2}$, which has the smallest Si nanocrystallite size of $5.2 \mathrm{~nm}$, the largest pore diameter of $1250 \mathrm{~nm}$ and the highest porosity of $80 \%$, shows the highest Raman peak shifting, about $3.2 \mathrm{~cm}^{-1}$. Based on our PL analysis, PL peaks of PS samples are related to the S-band, which extends in blue-red spectral range, and they show a blue shifting, about $5-12 \mathrm{~nm}$, over the wavelength range of $692-680 \mathrm{~nm}$, with increasing current density of $20-90 \mathrm{~mA} / \mathrm{cm}^{2}$. The best PL efficiency, around $680 \mathrm{~nm}$, is also observed for PS sample prepared at current density of $90 \mathrm{~mA} / \mathrm{cm}^{2}$, which can be attributed to QCE. According to the QCE, optical phonons confined in nanocrystals among the pore walls should be responsible for both Raman peak shifts and pronounced PL peaks with blue shifting, observed in our PS samples.

The PL blue shifting and Raman peak shifting, observed in our PS samples, which show an increase towards lower wavelengths and wavenumbers respectively, is a combined effect of the smaller Si nanocrystallite size (or higher porosity) and residual stress, yielding a slight increase in the lattice mismatch at PS/Si interface, in consistent with the QCE model.

In conclusion, by changing the applied current density, the light emitting and structural properties of PS samples can be controlled. These results suggest that the PS sample with finely controlled atomic-scale structure, is a good candidate for the potential applications in optoelectronic and sensor devices.

\section{Acknowledgments}

This work is supported by the Ege University, Research Project Foundation: Project no: 2013FEN058.

\section{References}

1. L. T. Canham, Appl. Phys. Lett. 57, 1046 (1990).

2. E. Vazsonyi et al., Thin Solid Films 388, 295 (2001).

3. Q. Chen et al., Phys. Lett. A 220, 293 (1996).

4. A. Shokrollahi and M. Zare, Optik 124, 855 (2013).

5. P. Steiner et al., Appl. Phys. Lett. 62, 2700 (1993).

6. T. Jalkanen et al., Sens. Actuators B 147, 100 (2010).

7. H. Zhang et al., Biosens. Bioelectron. 44, 89 (2013).

8. L. Tsybeskov et al., Phys. Rev. B 49, 7821 (1994).

9. A. G. Cullis and L. T. Canham, Nature 353, 335 (1991). 
10. V. Lehmann and U. Gösele, Appl. Phys. Lett. 58, 856 (1991).

11. P. Kumar, ISRN Nanotechnol. 2011, 163168 (2011).

12. B. Cho et al., Microelectron. Eng. 89, 92 (2012).

13. K. Behzad et al., Int. J. Electrochem. Sci. 7, 8266 (2012).

14. G. Gouadec and P. Colomban, Prog. Cryst. Growth Charact. Mater. 53, 1 (2007).

15. D. H. Ge et al., Electrochem. Commun. 12, 603 (2010).

16. X. Q. Bao et al., Electrochem. Commun. 9, 1991 (2007).

17. N. A. Asli et al., Adv. Mater. Res. 667, 324 (2013).

18. J. Peckham and G. T. Andrews, Semicond. Sci. Technol. 28, 105027 (2013).

19. M. D. Mason et al., Thin Solid Films 406, 151 (2002).

20. S. Li et al., J. Lumin. 146, 76 (2014).

21. S. Manotas et al., Thin Solid Films 401, 306 (2001).

22. D. H. Ge et al., Electrochim. Acta 88, 141 (2013).

23. M. Zare et al., Appl. Surf. Sci. 257, 9507 (2011).

24. J. Charrier et al., Appl. Surf. Sci. 253, 8632 (2007).

25. X. Q. Bao et al., Electrochem. Commun. 9, 1689 (2007).

26. X. G. Zhang, J. Electrochem. Soc. 151, 69 (2004).

27. F. Zhong and Z.-H. Jia, Physica B 411, 77 (2013).

28. B. Li et al., Phys. Rev. B 59, 1645 (1999).

29. R.-P. Wang et al., Phys. Rev. B 61, 16827 (2000).

30. Y. Kang et al., Opt. Lasers Eng. 43, 847 (2005).

31. C.-H. Cho et al., J. Korean Phys. Soc. 33, 292 (1998).

32. S. R. Goodes et al., Semicond. Sci. Technol. 3, 483 (1988).

33. C. S. Chang and J. T. Lue, Thin Solid Films 259, 775 (1995).

34. Q. Li et al., Opt. Lasers Eng. 48, 1119 (2010).

35. A. G. Cullis et al., J. Appl. Phys. 82, 909 (1997).

36. R. Tsu et al., Appl. Phys. Lett. 60, 112 (1992). 